\title{
Comparison of Steganography Using the Discrete Cosine Transform Method on Image Based Bilinear, Nearest Neighbor and Spline Interpolation
}

\author{
Garno $^{1}$, Adhi Rizal ${ }^{2}$, Arip Solehudin ${ }^{3}$, Reza Ekstanza ${ }^{4}$, Dadang Yusup ${ }^{5}$ \\ 1,2,3,4,5 Informatics Engineering, Universitas Singaperbangsa Karawang, Indonesia \\ ${ }^{1}$ garno@staff.unsika.ac.id, ${ }^{2}$ adhi.rizal@staff.unsika.ac.id \\ ${ }^{3}$ arip.solehudin@staff.unsika.ac.id, ${ }^{4}$ reza.ekstanza15123@student.unsika.ac.id, \\ ${ }^{5}$ dadang.dyfestaff.unsika.ac.id
}

\begin{abstract}
The research was conducted in the field of steganography. Discrete Cosine Transform (DCT) is a method used in the insertion technique. The results of steganography have problems if they look blurry, have low levels of similarity and high error values. One way to solve this problem is by proposing image interpolation. The interpolation method consists of various kinds and gives each other advantages. This study intends to compare three kinds of interpolation techniques to find the best one. The three interpolation techniques are bilinear, nearest neighbor, and spline. The method used in this research is experimental. Images with extension formats * .tif, * .png, and * .bmp with dimensions of $512 \times 512$ px are interpolated by scaling $1.5,2$, and 4 . The results of the interpolation process are used to insert messages in * .txt format of 157 bytes with discrete cosines transform (DCT). The image quality of the message insertion is measured by the MSE and PSNR values. The result of the message insertion test shows that the value of the image quality is directly proportional, meaning that if the condition of the message size is fixed and the cover dimensions are greater, the MSE value will be smaller and the PSNR value will be greater. Images with * .tif and * .bmp extension formats have good stability, * .png images vary in size. The smallest error value test results were obtained in the spline interpolation technique and this method when compared to the other two techniques had the lowest average MSE value of 8.221 and the PSNR value of $40,301 \mathrm{~dB}$.
\end{abstract}

Keywords: interpolation, discrete cosine transform (DCT), steganography, MSE, PSNR

\section{INTRODUCTION}

Steganography is a message insertion technique that utilizes images as a holding medium [1-2]. Steganography has various ways of inserting messages. The techniques used in message insertion are the least significant bit (LSB) [3-4], algorithms and transformations [5], redundant pattern encoding [6], and spread spectrum methods [6-10]. Many steganographic studies use these methods and provide mutual advantages. There is research on message insertion combined with the cover image's preparation process [1][3]. The preparation process affects the quality of the message insertion results. One of the preparation processes in the cover image is image interpolation. There are various pixel processing techniques for the cover image. Some interpolation techniques are classified as non-adaptive, and some are classified as adaptive [11-12]. Interpolation is used to scale the cover image in message insertion [11]. Other benefits of interpolation such as image super-resolution technique [13-16], image compression technique [10] image restoration [14-15].

Previous research by Zang et al. image processing used super-resolution. This study uses neighbors for image reconstruction. The proposed method is a new super resolution-based regression that overcomes the previous weaknesses of using anchored neighborhood regression [8]. Another study by Garno et al. made use of bilinear interpolation for pixel stretching. Research is used to solve most studies that insert messages only in the form of text sentences or in txt format only. The research conducted message insertion in doc / docx files, pdf files, compress RAR files containing sentences, images, and formula formulas with symbols. The test results obtained MSE values of $8.35 \mathrm{~dB}$ and PSNR $27.87 \mathrm{~dB}$ [16]. Another study using cubic b-spline for interpolation in cover images. This research applies the cubic $b$-spline method because the literature obtained is the best method. A cubic b-spline method can maintain positive $3 \mathrm{D}$ data visualization. The data is kept smooth and looks attractive. This study examines previous research conducted by Ki-Hyung Jung using neighbor interpolation. The results of the study provide a guarantee of PSNR above $35 \mathrm{~dB}$. Research in the journal discussed wants to keep the data file to image 
and not reduce the cover image quality. The results obtained a comparison of the MSE and PSNR values between the original image against the stego image. The results of the study were influenced by the dimensions of different images [17].

Research on Cubic B-spline interpolation and genetic algorithm proposed by Jiang and Chen. Interpolation is carried out on a 2-dimensional image on a grayscale. Genetic algorithms are used to detect the optimal tension parameter values to minimize errors. The results showed that the PSNR, SSIM, MS-SSIM, and FSIM were excellent and reliable. Interpolated BSpline lookup tables compared to Conventional BSpline are faster with less computation time than a factor of 5-6. The research method with the interpolation bilinear process is used to resize the original image. Initially, the image was resized to a smaller half scale, namely $512 \times 512$ to $256 \times 256 \mathrm{px}$, then the results were bilinear interpolated back to the size of $512 \times 512 \mathrm{px}$. The final result is used as a cover in the steganography process - the process of inserting a message that has been encrypted by a magic rectangle using LSB substitution. The study obtained an average PSNR value of $52.3851 \mathrm{~dB}$ [9].

The studies that are studied have contributed various advantages. The methods proposed have varied results. There are various contributions, such as accuracy value, faster processing time limit, knowledge contribution, formula contribution, increase in similarity value / PSNR, small error / MSE, and others. Many studies have examined non-adaptive interpolation in digital images because it maintains the integrity of image information. It is called non-adaptive interpolation because the computation is evenly distributed on all pixels [18]. So this study proposes a comparative test of the methods used for image interpolation of the nonadaptive type. The urgency of the research to compare non-adaptive methods is to obtain the best interpolation method and still retain image information. The interpolation method is bilinear, nearest neighbor, and spline interpolation. The results of each interpolation are then used for message insertion. If the more similar to the original image or the greater the PSNR value, the higher the data security level. As the goal of steganography, which is not realizing it or not detecting it in the image, there is a message. Discrete cosine transform (DCT) is used as the insertion method.

\section{METHOD}

Before the steganography process, other preparations were carried out, namely the preparation of research materials and tools. The research material is in the form of * tif * .png, and * .bmp digital images as the cover image. The message that is inserted is in the form of text, which is a message file with the name "pesanrahasia1.txt," measuring 157 bytes. The contents of the message are inserted, namely the name and address of the campus and research tools in the form of Matlab 2019a software.

The essence of steganographic research is carried out in three main process stages. The main process stages are the interpolation process on the cover image, the DCT steganography process, and the steganography result quality test process. As for convenience, it can be seen in Fig. 1.

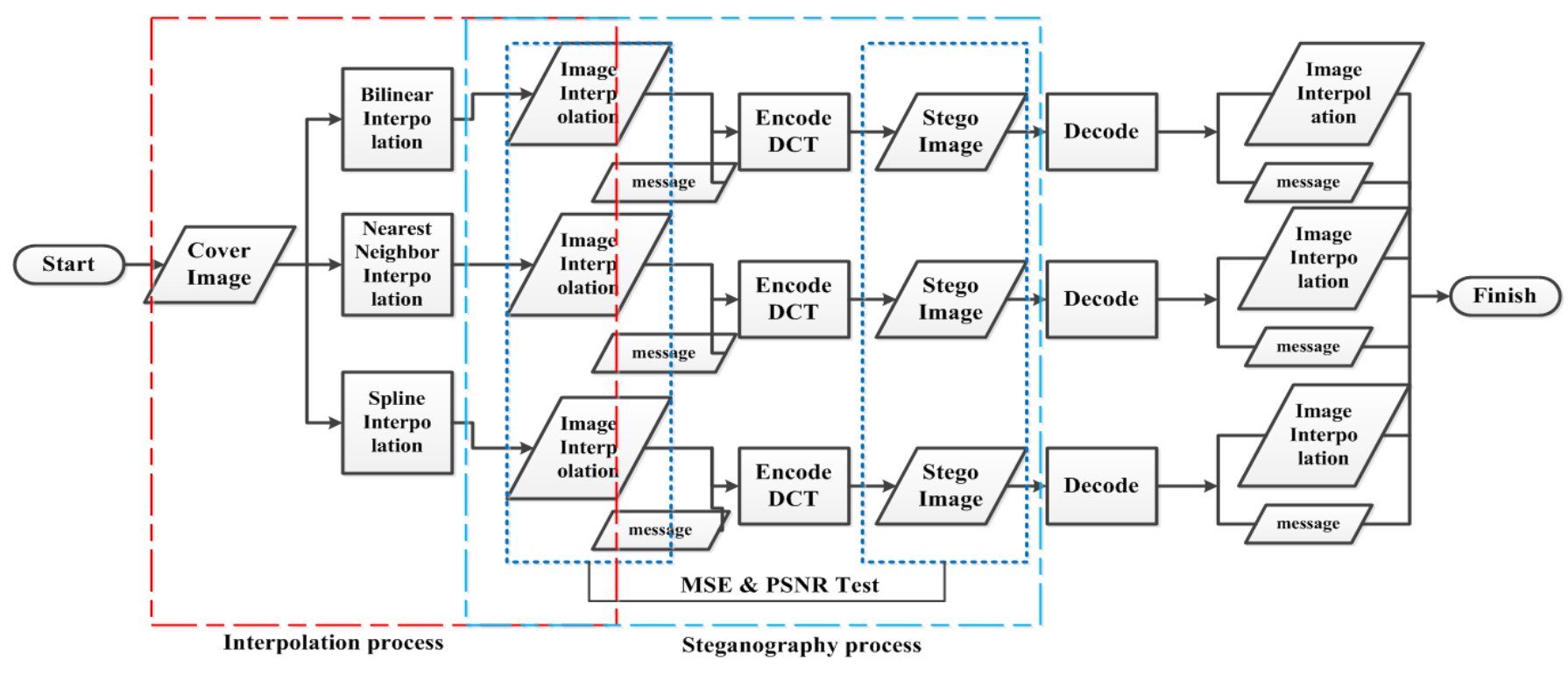

Fig.1 Process steganography methods 


\section{A. Cover Image Interpolation Process}

Interpolation process as shown in Figure 1 part in the red dotted line. The interpolation process is carried out as the first step in the preparation of the process. Interpolation is carried out on each cover image in the format * .tif, * .png, * .bmp, with three methods used: bilinear interpolation, nearest neighbor, and spline.

The working principle of bilinear (bi) interpolation is the average weight value of 4 pixels around it to fill the empty interpolated pixels. The four pixels are derived from the nearest $2 \times 2$ pixel values with known values surrounding the unknown pixel. Then look for the average value of the 4 pixels to fill. The bilinear interpolation technique works in both horizontal and vertical directions. When all known pixel distances are equal, the interpolated value is simply the number of them divided by four [10], [16-17].

The working principle of the nearest neighbor interpolation (nni), namely the digital image or new scale can be smaller, bigger or the same size. This is due to the scale ratio applied. What happens during the process is that when the digital image scaling operation is applied, an empty space is formed called an empty pixel on the original image. Empty pixels will be filled with color pixels that match the color pixels of the closest neighboring neighbors. This means that the nearest neighbor interpolation does not produce a new pixel value, but instead fills in the pixel gaps with the nearest neighbor pixel value. The resulting pixel has the same value as the nearest neighboring pixel [15], [1821].

Spline (si) interpolation works to get an unknown value with the help of a known value. The spline interpolates these values as closely as possible to the original values. Interpolate the image with a cubic spline using 25 subpixel locations in the calculation, thus increasing the more acceptable pixels. Spline itself is pieces of a polynomial function with derivatives that meet certain continuity constraints. When $\mathrm{k}=1$, the spline is called a linear spline. When $\mathrm{k}=2$, the spline is called a quadratic spline. When $\mathrm{k}=3$, the spline is called a cubic spline. Spline interpolation uses higherorder, i.e. considers many surrounding pixels and intensively reconsiders them. The higher the degree of spline, the more stable and smooth the characteristics [13], [17],[22].

The interpolation process results for each scheme are in the form of an integrated image, and no image format changes are made. The interpolation process is carried out by enlarging the digital cover image's dimensions or the initial image enlarged to an enlargement scale.

\section{B. Process Steganography Discrete Cosine Transform (DCT)}

The second step is the process of inserting the message into the image interpolation. The schematic of the steganographic process is depicted in the area in blue dotted lines in figure 1. The DCT method can be used to insert messages to convert a signal into its basic frequency components. Algorithms and transformations in steganography hide data in mathematical functions [16][22]. DCT works with a matrix transformation, namely, converting a discrete signal from the time domain into a frequency domain. A two-dimensional matrix $\mathrm{S}(\mathrm{x}, \mathrm{y})$ where $\mathrm{x}=0,1, \ldots, \mathrm{n}-1$ and $\mathrm{y}=0,1, \ldots$, $\mathrm{m}-1$ can be transformed into the frequency domain using the DCT (1).

$$
S(u, v)=C(u) C(v) \sum_{x=0}^{n=1} \sum_{y=0}^{m=1} S(x, y) \cos \left\lfloor\frac{\pi(2 x+1) u}{2 n}\right\rfloor \cos \left\lfloor\frac{\pi(2 y+1) v}{2 m}\right\rfloor
$$

with $u=0,1, \ldots, n-1$ and $v=0,1, \ldots, m-1$;

Information:

$$
C(u)=C(v)\left\{\begin{array}{l}
\sqrt{\frac{1}{n}} ; \text { for } u=v=0 \\
\sqrt{\frac{2}{n}} ; \text { for others }
\end{array}\right.
$$

$\mathrm{S}(\mathrm{u}, \mathrm{v})$ : Data on the frequency domain

$\mathrm{S}(\mathrm{x}, \mathrm{y})$ : Data on the space domain $\mathrm{u}, \mathrm{v} \quad$ : The coordinates of the pixels for the transformation block

$\mathrm{x}, \mathrm{y}$ : The coordinates of the pixels for the pretransformed image

C (u) : The value of the transform domain coefficient at the coordinate $\mathrm{u}$

$\mathrm{C}$ (v) : The value of the transform domain coefficient at the coordinate $\mathrm{u}$

n : The number of lines in the block to transform

$\mathrm{m} \quad$ : The number of lines in the block to transform 


\section{Quality Test of Steganography Results}

The last process is to test the quality of the steganography results. Test results and discussion focused on stegoimage quality. The values of Mean Square Error (MSE) and Peak Signal to Noise Ratio (PSNR) are the parameters used [14]. The PSNR value is measured in decibels (dB), and MSE is based on (2).

$$
P S N R=10 \log _{10}\left(\frac{C^{2} \max }{M S E}\right)
$$

with $M S E=\frac{1}{M . N} \sum_{x=1}^{M} \sum_{y=1}^{N}\left(S_{x y}-C_{x y}\right)^{2}$

Information:

$C_{\max }=$ the largest pixel value in the whole image $x$ and $y=$ the coordinates of a point on the image $M$ and $N=$ dimensions of the image

$S=$ embedded image(stegoimage)

$C=$ original image (coverimage)
The MSE and PSNR test processes are depicted in areas marked with blue dotted lines in figure 1 . Although the process is decoding / extracting messages from image interpolation, this is not the case for writing and discussion in this journal.

\section{RESULTS AND DISCUSSION}

\section{A. Result of the Steganography Process}

A cover image that has been interpolated into an interpolation image is used as a container for inserting messages. The message inserted is a message "pesanrahasia1.txt" with a size of 157 bytes and contains the text of the name and address of the campus. The encoding results with Discrete Cosine Transform (DCT) on the interpolation image are presented in Tables I to III.

TABLE I

STEGANOGRAPHY WITH DCT IN TIF IMAGE

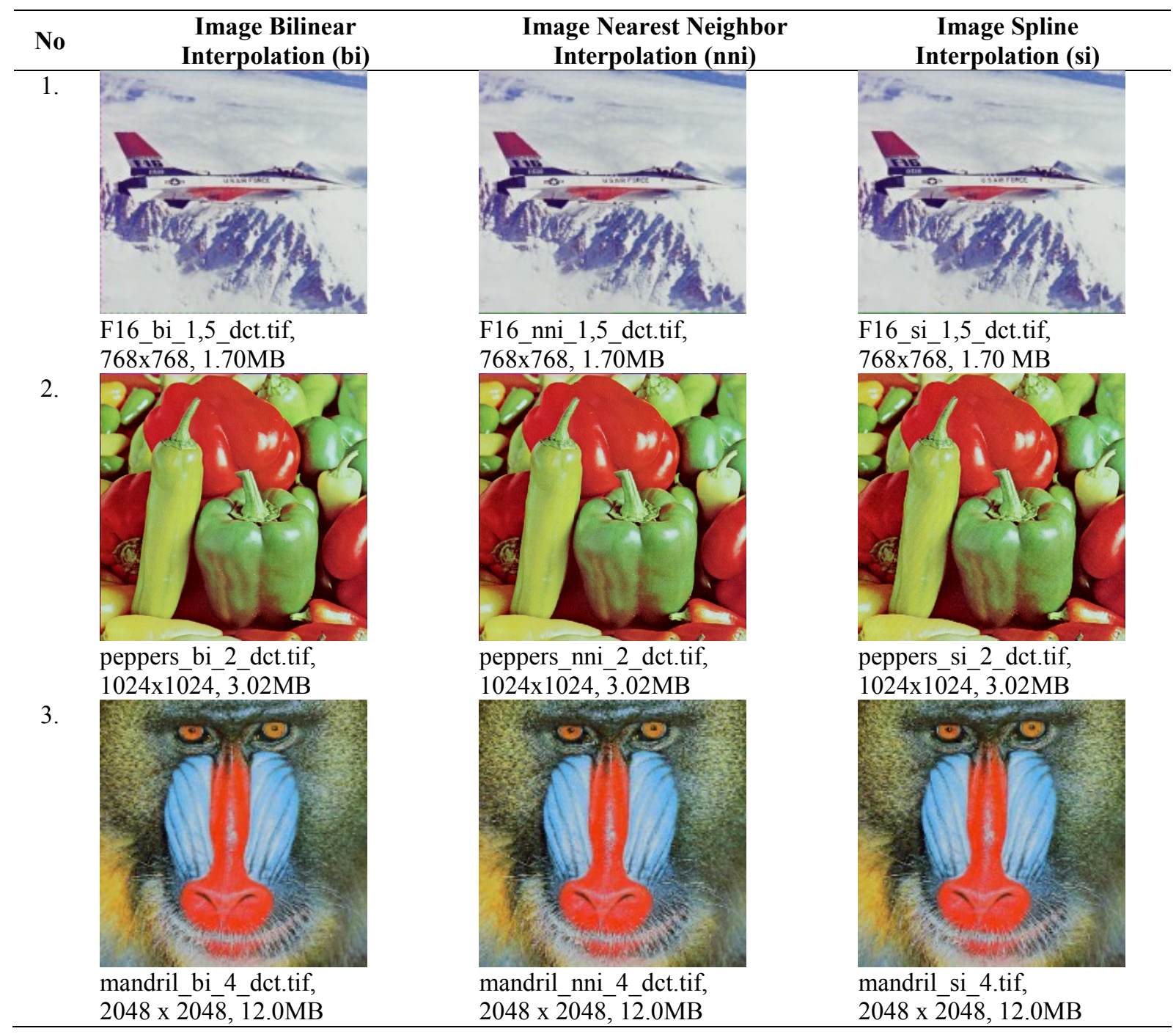


Based on Table I, steganography based bilinear, nearest neighbor, and spline with scaling 1.5, 2, and 4 on the F16 dot tif image, peppers dot tif and mandril dot tif with 157 bytes of messages inserted, all did not change the dimensions or size.

Based on Table II steganography based bilinear, nearest neighbor and spline with scaling 1.5, 2, and 4 on the dot png image. The image is inserted with a message of 157 bytes and changes in size. However, the image dimensions do not change.

Based on Table III, steganography-based bilinear, nearest neighbor and spline with scaling $1.5,2$, and 4 in the image with dot BMP extension, 157 bytes of messages are inserted without changing the dimensions or size.

TABLE II

STEGANOGRAPHY WITH DCT IN PNG IMAGE

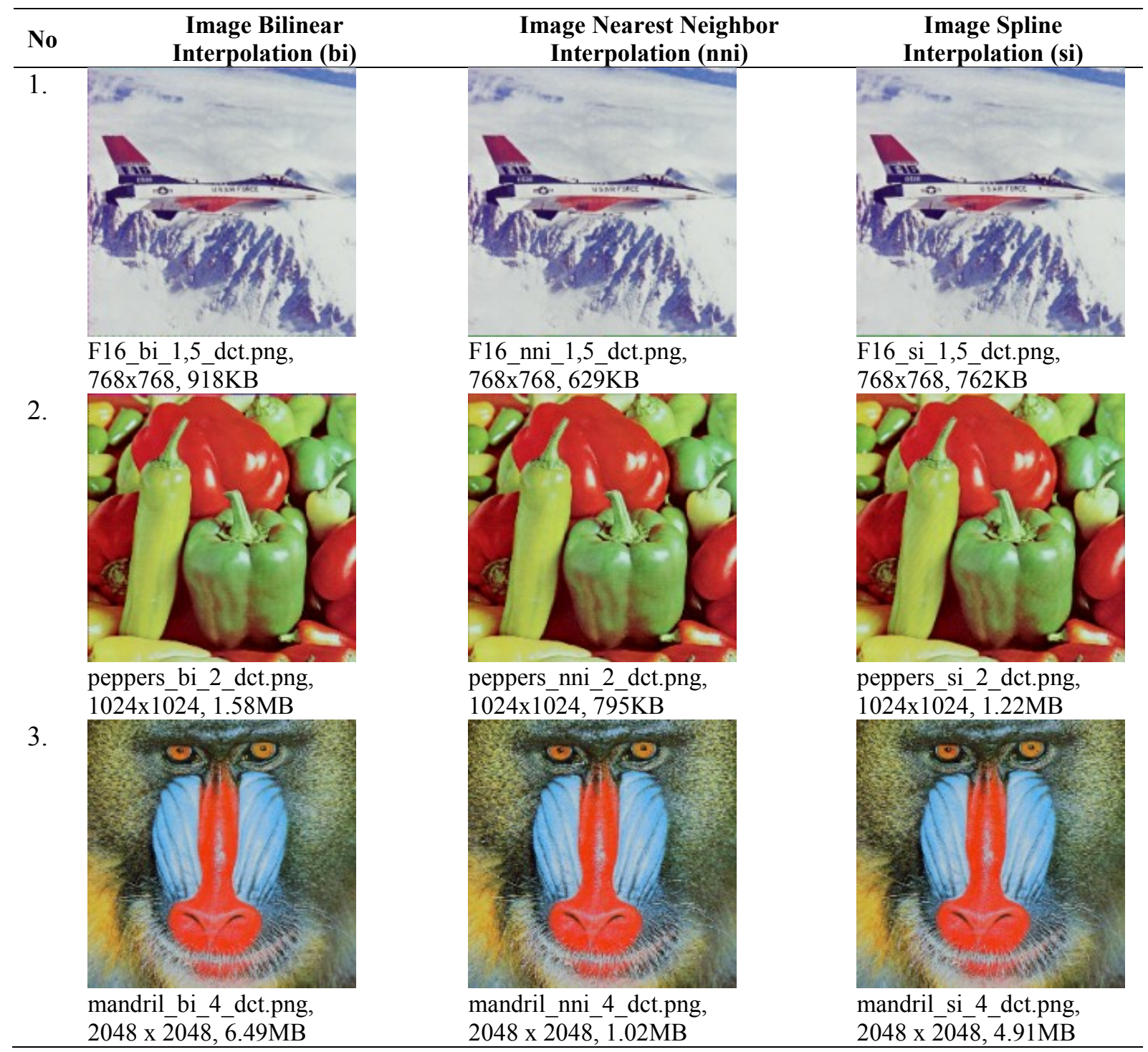


TABLE III

STEGANOGRAPHY WITH DCT IN BMP IMAGE

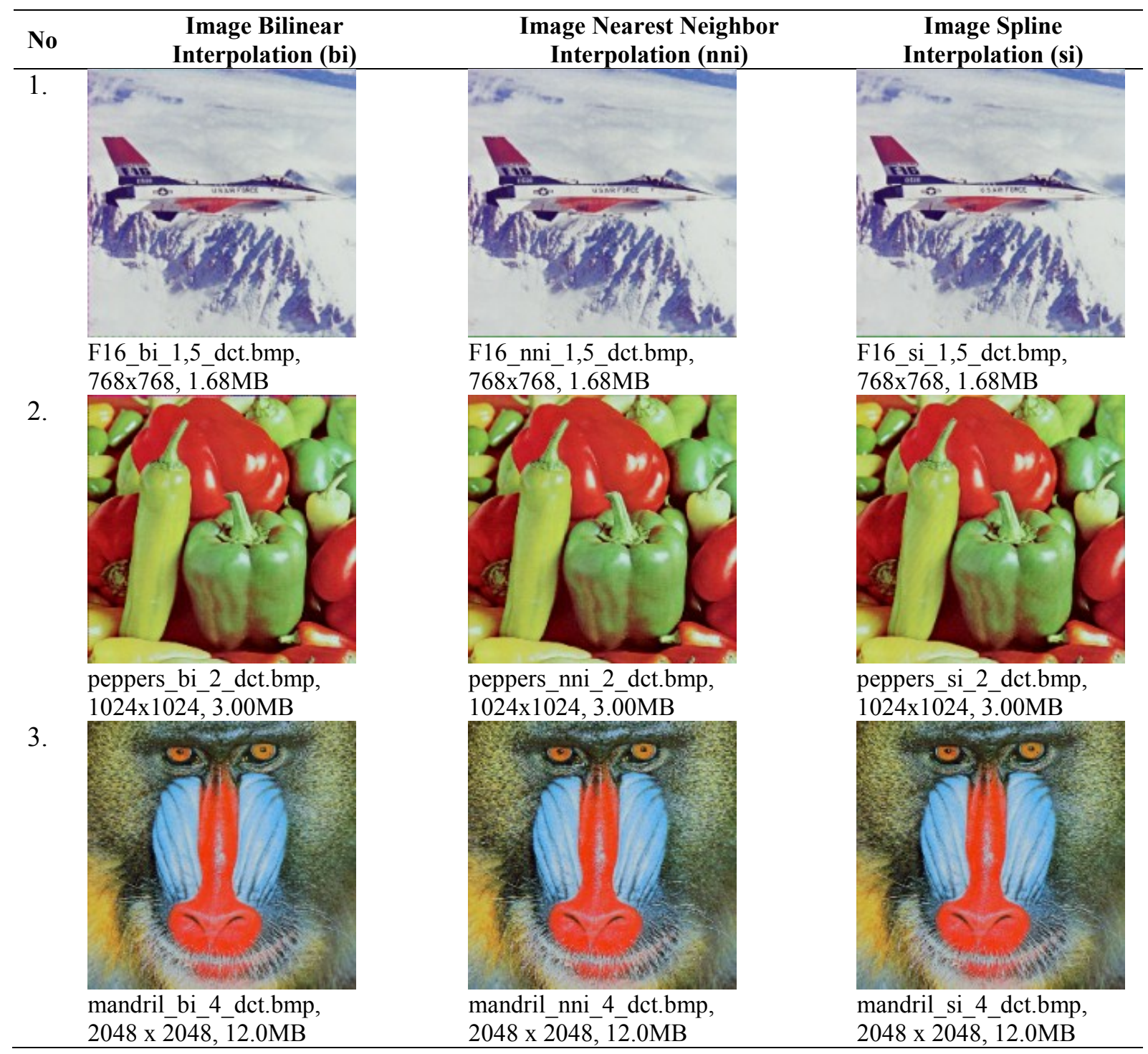

\section{B. MSE and PSNR Test}

The steganography has been completed, and then the stegoimage quality test is carried out. Stegoimage and image interpolation are used to measure the level of error (MSE) and similarity (PSNR). The results of the MSE and PSNR tests on image interpolation against stegoimage are presented in Table IV.

Based on Table IV, the results of MSE and PSNR steganography tests on bilinear interpolation-based cover media obtained PSNR values of $40,280 \mathrm{~dB}$ and MSE 8,243. The nearest neighbor-based covers get PSNR scores of $40.297 \mathrm{~dB}$ and MSE 8.223, and spline- based covers get PSNR values of 40.301 and MSE 8.221 .

MSE and PSNR analysis on interpolation-based images (bilinear, nearest neighbor, and spline), namely if the scale gets bigger and the message size is fixed, the results are directly proportional. The meaning is directly proportional, namely the greater the PSNR value and the smaller the MSE. If the scale is getting smaller, the result will be that the MSE value is getting bigger. The PSNR value is getting smaller, and comparing the test results of 3 types of interpolation to the cover image obtained spline interpolation giving the largest PSNR and the smallest MSE. 
TABLE IV

MSE AND PSNR INTERPOLATION

\begin{tabular}{|c|c|c|c|c|c|c|c|c|c|}
\hline \multirow[b]{2}{*}{ No } & \multicolumn{3}{|c|}{ Image Testing bi } & \multicolumn{3}{|c|}{ Image Testing nni } & \multicolumn{3}{|c|}{ Image Testing si } \\
\hline & Image & MSE & $\begin{array}{c}\text { PSNR } \\
\text { (dB) }\end{array}$ & Image & MSE & $\begin{array}{l}\text { PSNR } \\
\text { (dB) }\end{array}$ & Image & MSE & $\begin{array}{c}\text { PSNR } \\
\text { (dB) }\end{array}$ \\
\hline 1. & $\begin{array}{l}\text { F16_bi_1,5_dc } \\
\text { t.tif }\end{array}$ & 14.89 & 36.40 & $\begin{array}{l}\text { F16_nni_1,5_- } \\
\text { dct.tif }\end{array}$ & 14.88 & 36.40 & $\begin{array}{l}\text { F16_si_1,5_dc } \\
\text { t.tif }\end{array}$ & 14.89 & 36.40 \\
\hline 2. & $\begin{array}{l}\text { peppers_bi_2 } \\
\text { dct.tif }\end{array}$ & 7.92 & 39.14 & $\begin{array}{l}\text { peppers_nni_2 } \\
\text { det.tif }\end{array}$ & 7.88 & 39.16 & $\begin{array}{l}\text { peppers_si_2 } \\
\text { dct.tif }\end{array}$ & 7.82 & 39.23 \\
\hline 3. & $\begin{array}{l}\text { mandril_bi_4__ } \\
\text { dct.tif }\end{array}$ & 1.92 & 45.30 & $\begin{array}{l}\text { mandril_nni_4 } \\
\text { dct.tif }\end{array}$ & 1.91 & 45.33 & $\begin{array}{l}\text { mandril_si_4_- } \\
\text { dct.tif }\end{array}$ & 1.91 & 45.32 \\
\hline 4. & $\begin{array}{l}\text { F16_bi_1,5_dc } \\
\text { t.png }\end{array}$ & 14.89 & 36.40 & 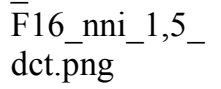 & 14.88 & 36.40 & $\begin{array}{l}\text { F16_si_1,5_dc } \\
\text { t.png }\end{array}$ & 14.89 & 36.40 \\
\hline 5. & $\begin{array}{l}\text { peppers_bi_2 } \\
\text { dct.png }\end{array}$ & 7.5 & 4 & $\begin{array}{l}\text { peppers_nni_2 } \\
\text { _dct.png }\end{array}$ & 7.88 & 39.16 & $\begin{array}{l}\text { peppers_si_2 } \\
\text { dct.png }\end{array}$ & 7.89 & 39.16 \\
\hline 6. & $\begin{array}{l}\text { mandril_bi_4_- } \\
\text { dct.png }\end{array}$ & 1 . & 4 & $\begin{array}{l}\text { mandril_nni_4 } \\
\text { _dct.png }\end{array}$ & 1 & 45.33 & $\begin{array}{l}\text { mandril_si_4_- } \\
\text { dct.png }\end{array}$ & 1.91 & 45.32 \\
\hline 7. & $\begin{array}{l}\text { F16_bi_1,5_dc } \\
\text { t.bmp }\end{array}$ & 14.8 & 40 & $\begin{array}{l}\overline{\mathrm{F}} 16 \_\mathrm{nni}{ }_{\text {ind }} 1,5 \\
\text { dct.bmp }\end{array}$ & 14.8 & 36 & $\begin{array}{l}\text { F16_si_1,5_dc } \\
\text { t.bmp }\end{array}$ & 14.88 & 36.40 \\
\hline 8. & $\begin{array}{l}\text { peppers_bi_2 } \\
\text { dct.bmp }\end{array}$ & 7 & 4 & $\begin{array}{l}\text { peppers_nni_2 } \\
\text { dct.bmp }\end{array}$ & 7.88 & 3 & $\begin{array}{l}\text { peppers_si_2 } \\
\text { dct.bmp }\end{array}$ & 89 & 39.16 \\
\hline 9. & $\begin{array}{l}\text { mandril_bi_4__ } \\
\text { dct.bmp }\end{array}$ & 1.5 & 45.30 & $\begin{array}{l}\text { mandril_nni_4 } \\
\text { dct.bmp }\end{array}$ & 1.5 & 45.33 & $\begin{array}{l}\text { mandril_si_4_- } \\
\text { dct.bmp }\end{array}$ & 1.91 & 45.32 \\
\hline \multicolumn{2}{|c|}{ Average } & 8.243 & 40.280 & & 8.223 & 40.297 & & 8.221 & 40.301 \\
\hline
\end{tabular}

\section{CONCLUSION}

The conclusion of the three interpolation techniques, namely bilinear, nearest neighbor, and spline, can be seen with the naked eye that there is no visible difference. However, if you use a test priority scale, it can be said that the spline interpolation technique is the most appropriate if it is seen from the smallest error value. Compared with the other two techniques, this spline method has the lowest average MSE value of 8,221 and the highest average PSNR value of 40,301 $\mathrm{dB}$. The suggestions in question include choosing a more diverse container object. It can be in the form of audio, video, or even text. Increase the selection of images in the steganography process. *. Gif, * .psd, * .pdf, * .raw and the like, object selection messages with a wider variety, which can be in the form of text and image-based doc / docx files, text and image-based pdf files, excel files with multiple sheets, compressed files with multiple contents, and even images, audio, and video.

\section{REFERENCES}

[1] G. Garno, R. I. Adam, and D. Yusup, "Perpaduan Interpolasi Bilinear dan Least Significant Bit pada Citra Digital dalam Teknik Steganografi," Telematika, vol. 12, no. 1, p. 59, 2019, doi: 10.35671/telematika.v12i1.766.
[2] N. Rismawati, "Analisis dan Perancangan Simulasi Enkripsi dan Dekripsi pada Algoritma Steganografi untuk Penyisipan Pesan Text pada Image menggunakan Metode Least Significant Bit (LSB) Berbasis Cryptool2," Fakt. Exacta, vol. 12, no. 2, pp. 132-144, 2019, doi: 10.30998/faktorexacta.v12i2.3527.

[3] D. R. I. M. Setiadi, "Improved payload capacity in LSB image steganography uses dilated hybrid edge detection," J. King Saud Univ. - Comput. Inf. Sci., no. xxxx, 2019, doi: 10.1016/j.jksuci.2019.12.007.

[4] P. Malathi and T. Gireeshkumar, "Relating the Embedding Efficiency of LSB Steganography Techniques in Spatial and Transform Domains," Procedia Comput. Sci., vol. 93, no. September, pp. 878885, 2016, doi: 10.1016/j.procs.2016.07.270.

[5] M. Ramalingam, N. A. Mat Isa, and R. Puviarasi, "A secured data hiding using affine transformation in video steganography," Procedia Comput. Sci., vol. 171, no. 2019, pp. 1147-1156, 2020, doi: 10.1016/j.procs.2020.04.123.

[6] R. S. Gulo, R. L. Simangunsong, S. B. K. Tafonao, M. Yusuf, and Yennimar, "Comparison of Spread Spectrum with Redundant Pattern Coding In Securing Text Messages Into Audio," J. Mantik, vol. 4, no. 2, pp. 1237-1242, 2020, [Online]. Available: http://iocscience.org/ejournal/index.php/mantik/article/v iew/882/595.

[7] H. Februariyanti, Wahyudi, A. Susanto, and Rihartanto, "Steganografi Pesan Terenkripsi Affine Cipher 
Menggunakan Metoda LSB Dengan Pola Genap Ganjil," Proceeding SINTAK, pp. 411-419, 2019.

[8] Z. Zhang et al., "Single image super resolution via neighbor reconstruction," Pattern Recognit. Lett., vol. 125, pp. 157-165, 2019, doi: 10.1016/j.patrec.2019.04.021.

[9] C. Jiang and Q. Chen, "Construction of blind restoration model for super-resolution image based on chaotic neural network," Chaos, Solitons and Fractals, vol. 131, no. Xxxx, p. 109498, 2020, doi: 10.1016/j.chaos.2019.109498.

[10] F. Li, K. Wu, C. Qin, and J. Lei, "Anti-compression JPEG steganography over repetitive compression networks," Signal Processing, vol. 170, p. 107454, 2020, doi: 10.1016/j.sigpro.2020.107454.

[11] A. Rohmani and S. Wibowo, "Rekayasa Perancangan Penyembunyian Pesan File Dan Text dengan Metode Enkripsi Des dan Enkripsi RC4," Techno.COM, vol. 15, no. 4, pp. 369-378, 2016.

[12] M. luthfi , I. F. Aksani , Manurung, "Studi Dan Implementasi Steganografi Pada Citra Jpeg Dengan Metode Spread Spectrum," JIKA (Jurnal Inform., vol. 1, no. 2, pp. 55-64, 2017, doi: 10.31000/jika.v1i2.539.

[13] A. Malik et al., "Reversible data hiding in homomorphically encrypted image using interpolation technique," J. Inf. Secur. Appl., vol. 48, pp. 1-7, 2019, doi: 10.1016/j.jisa.2019.102374.

[14] M. Kaur and V. K. Attri, "Implementation of Steganographic Method based on Interpolation and LSB Substitution of Digital Images with Watermarking and Visual Cryptography," Int. J. Comput. Appl., vol. 121, no. 21, pp. 7-12, 2015, doi: 10.5120/21822-5073.

[15] S. K. Dhara and D. Sen, "Across-scale process similarity based interpolation for image super- resolution," Appl. Soft Comput. J., vol. 81, p. 105508, 2019, doi: 10.1016/j.asoc.2019.105508.

[16] G. Garno and A. Solehudin, "Teknik Steganografi dengan Metode Discrete Cosines Transform (DCT) pada Citra Interpolasi Bilinear untuk Pengamanan Pesan," J. Inform. Upgris, vol. 3, no. 2, pp. 116-121, 2017, doi: $10.26877 /$ jiu.v3i2.1815.

[17] G. Garno and R. I. Adam, "Skema Penyembunyian Data pada Gambar Berbasis Interpolasi Kubik B-Spline Menggunakan Metode Least Significant Bit (LSB)," J. Edukasi dan Penelit. Inform., vol. 5, no. 3, p. 255, 2019, doi: 10.26418/jp.v5i3.37584.

[18] S. H. Mahajan and V. K. Harpale, "Adaptive and nonadaptive image interpolation techniques," Proc. - 1st Int. Conf. Comput. Commun. Control Autom. ICCUBEA 2015, pp. 772-775, 2015, doi: 10.1109/ICCUBEA.2015.154.

[19] S. A. Parah et al., Secure and reversible data hiding scheme for healthcare system using magic rectangle and a new interpolation technique. Elsevier Inc., 2019.

[20] P. P. S. Parsania and D. P. V.Virparia, "A Review: Image Interpolation Techniques for Image Scaling," Int. J. Innov. Res. Comput. Commun. Eng., vol. 02, no. 12, pp. 7409-7414, 2015, doi: 10.15680/ijircce.2014.0212024.

[21] E. A. Mittal, E. Inderpreet, and E. J. Kaur, "Futuristic schematic image interpolation," Ijarece, vol. 5, no. 5, pp. 1357-1360, 2016.

[22] S. Abbas, M. Z. Hussain, and M. Irshad, "Image interpolation by rational ball cubic B-spline representation and genetic algorithm," Alexandria Eng. $J$. vol. 57, no. 2, pp. 931-937, 2018, doi: 10.1016/j.aej.2017.01.004. 